\title{
Dehydrocostus lactone suppresses cell growth and induces apoptosis in recombinant human papilloma virus-18 HaCaT cells via the PI3K/Akt signaling pathway
}

\author{
WEI LI ${ }^{1}$, YI BING MA ${ }^{1}$, YING QIU MAO ${ }^{2}$ and TONG LIN ${ }^{3}$ \\ ${ }^{1}$ Department of Dermatology; ${ }^{2}$ Institute of Traditional Chinese Medicine; ${ }^{3}$ Department of Gynecology, \\ Dongfang Hospital, Beijing University of Chinese Medicine, Beijing 100029, P.R. China
}

Received February 24, 2017; Accepted August 16, 2017

DOI: $10.3892 / \mathrm{mmr} .2018 .8805$

\begin{abstract}
Dehydrocostus lactone is considered to be the major cholagogic ingredient of the Costus genus of plants. It exhibits strong cholagogic effects, and also exerts antimicrobial and antineoplastic activity. The present study aimed to investigate the effects of dehydrocostus lactone on the cell growth and apoptosis of recombinant human papilloma virus (HPV)-18 $\mathrm{HaCaT}$ cells. The HPV-18 genome was transfected into $\mathrm{HaCaT}$ cells, which were subsequently used for analysis. The results demonstrated that dehydrocostus lactone reduced the cell proliferation and induced apoptosis of HPV-18 HaCaT cells, as determined by MTT and N-acetyl-Asp-Glu-Val-Asp p-nitroanilide assays, respectively. Furthermore, caspase-3/9 activity was determined using a caspase-3/9 activity kit and western blotting was performed to investigate the expression of certain proteins. The results demonstrated that caspase-3/9 activities, and the protein expression of $\mathrm{Bcl}-2$-associated $\mathrm{X}$ and $\mathrm{p} 53$, in HPV-18 HaCaT cells were significantly increased, while cyclin D1 protein expression was suppressed by dehydrocostus lactone. Additionally, dehydrocostus lactone significantly upregulated the protein expression of phosphatase and tensin homolog and inhibited the phosphatidylinositol 3-kinase (PI3K)/Akt signaling pathway in HPV-18 HaCaT cells. Therefore, the results of the present study indicate that dehydrocostus lactone may suppress cell growth and induce apoptosis in recombinant HPV-18 HaCaT cells via the PI3K/Akt signaling pathway, and may be a represent a novel potential therapeutic agent for the treatment of condyloma acuminatum.
\end{abstract}

Correspondence to: Dr Wei Li, Department of Dermatology, Dongfang Hospital, Beijing University of Chinese Medicine, 6 Fangxingyuan 1st Block, Beijing 100029, P.R. China

E-mail: wzuz6442702@126.com

Key words: dehydrocostus lactone, human papilloma virus-18 $\mathrm{HaCaT}$, condyloma acuminatum, phosphatidylinositol 3-kinase/Akt

\section{Introduction}

Condyloma acuminatum (CA) is a common sexually transmitted disease that is caused by infection with human papilloma virus (HPV) (1), and its incidence is increasing annually. Clinically, it presents as cauliflower-like or papillary growths in the genital area. Although it is a benign hyperplasia, certain cases may transform into malignant tumors (1). A minority of cases may develop large CA due to excessive hyperplasia in a short period of time. CA is very infectious (2), and has a negative impact on society and the family of patients as it adversely affects the physical and mental health of patients. High relapse rates are an issue following CA treatment (3), and it is extremely difficult to control the transmission and prevalence of the disease (3). Therefore, this disease has attracted attention in research.

Humans are the only natural host of HPV. Three types of squamous epithelial cells on human skin, mucosa and metaplasia are sensitive to HPV, which infects them via damaged squamous epithelial cells (4). Studies have reported that after human squamous epithelial cells are infected with HPV, cells exhibit abnormal proliferation and apoptosis $(4,5)$. The specific mechanism underlying the development of CA abnormal growths following HPV infection has not previously been identified, however, increased cell division or reduced cell death following HPV infection may be implicated (6). Tumor necrosis factor-related apoptosis-inducing ligand led to the apoptosis of tumor cells, virus-infected cells and transformed cells (6). Caspase-3 is an established death protease (6) that is a key protein in the apoptosis pathway, and participates in cell apoptosis induced by a variety of factors (4).

The phosphatidylinositol 3-kinase (PI3K)/Akt pathway is a typical signal transduction pathway that inhibits cell apoptosis and promotes cell survival (7). In addition, the pathway has a key role in the resistance of tumors to chemotherapy and radiotherapy, the genesis and proliferation of tumor cells, and the invasiveness and metastasis of tumor cells to other tissues (8). The PI3K/Akt signaling pathway is an essential pathway in cells. Specifically, it has an important role in the genesis and development of CA cells (8). Studies have demonstrated that the PI3K/Akt pathway induces CA through various mechanisms: The pathway inhibits the 
expression of protein $\mathrm{p} 53$, a tumor suppressor gene, in the cell nucleus by promoting the anti-nuclear movement of $\mathrm{Mdm} 2$ proto-oncogene; therefore, excessive activation of the PI3K signaling pathway leads to uncontrollable proliferation of CA cells. Additionally, the pathway inhibits the cell apoptosis process via the phosphorylation of various proteins, including Bcl-2-associated agonist of cell death, caspase-9 and other components of the apoptosis pathway, and also inhibits conformational changes of certain apoptosis proteins, such as Bcl-2-associated X (Bax) (8-10).

Dehydrocostus lactone, the structure of which is presented in Fig. 1, is extractable from dry Costus root. Costus originated from India, and was introduced and cultivated in the province of Yunnan in China $(11,12)$. Dehydrocostus lactone is the major ingredient of Costus root essential oil (13). It has been demonstrated through modern pharmacological studies that Costus has certain effects on the digestive, respiratory and cardiovascular systems (14). Dehydrocostus lactone, as the primary component of Costus, has been reported to improve intestinal functions, promote gastric motility and choleresis, and exhibit antidiarrheic, antihypertensive and antibacterial effects (15). The aim of the present study was to investigate the effects of dehydrocostus lactone on the cell growth and apoptosis of recombinant HPV-18 $\mathrm{HaCaT}$ cells, and to determine whether these effects may occur via the PI3K/Akt signaling pathway.

\section{Materials and methods}

Cell lines and transfection of the HPV-18 genome into $\mathrm{HaCaT}$ cells. The HaCaT human epithelial cell line was purchased from the Shanghai Cell Bank of Chinese Academy of Sciences (Shanghai, China), propagated in Dulbecco's modified Eagle's medium (DMEM; Thermo Fisher Scientific, Inc., Waltham, MA, USA) and then supplemented with $10 \%$ heat-inactivated fetal bovine serum (Gibco; Thermo Fisher Scientific, Inc.), $100 \mathrm{U} / \mathrm{ml}$ of penicillin and $100 \mathrm{mg} / \mathrm{ml}$ of streptomycin at $37^{\circ} \mathrm{C}$ in an humidified atmosphere containing 95\% air and $5 \% \mathrm{CO}_{2}$. A total of $200 \mathrm{ng}$ of HPV-18 expression plasmid was purchased from Sangon Biotech Co., Ltd. (Shanghai, China) and transfected into cells $\left(1 \times 10^{6}\right.$ cell/well $)$ using Lipofectamine ${ }^{\circledR} 2000$ (Invitrogen; Thermo Fisher Scientific, Inc.). After 4 h, the medium was replaced with fresh DMEM medium supplemented with dehydrocostus lactone (Sigma-Aldrich; Merck KGaA; Darmstadt, Germany). Following a $48 \mathrm{~h}$ incubation at $37^{\circ} \mathrm{C}$, the Caspase-3 and caspase- 9 expression levels were investigated via western blot analysis and following a $72 \mathrm{~h}$ incubation at $37^{\circ} \mathrm{C}$, the MTT assay was performed.

MTT assay. Recombinant HPV-18 HaCaT cells $\left(1 \times 10^{6}\right.$ cells/well $)$ were seeded in 96-well plates and treated with either $2 \mu \mathrm{l}$ of dimethyl sulfoxide (DMSO) or $2 \mu \mathrm{l}$ of dehydrocostus lactone $(2.5,5$ and $10 \mu \mathrm{g} / \mathrm{ml})$ for $0,24,48$ and $72 \mathrm{~h}$ at $37^{\circ} \mathrm{C}$. Following treatment, MTT tetrazolium salt $(0.5 \mathrm{mg} / \mathrm{ml}$; Sigma-Aldrich; Merck KGaA) was added for $4 \mathrm{~h}$. The medium was then removed and $150 \mu \mathrm{l}$ DMSO was added per well to dissolve the formazan crystals. Absorbance was measured using the SpectraMax 190 microplate reader (Molecular Devices, LLC., Sunnyvale, CA, USA) at $490 \mathrm{~nm}$.

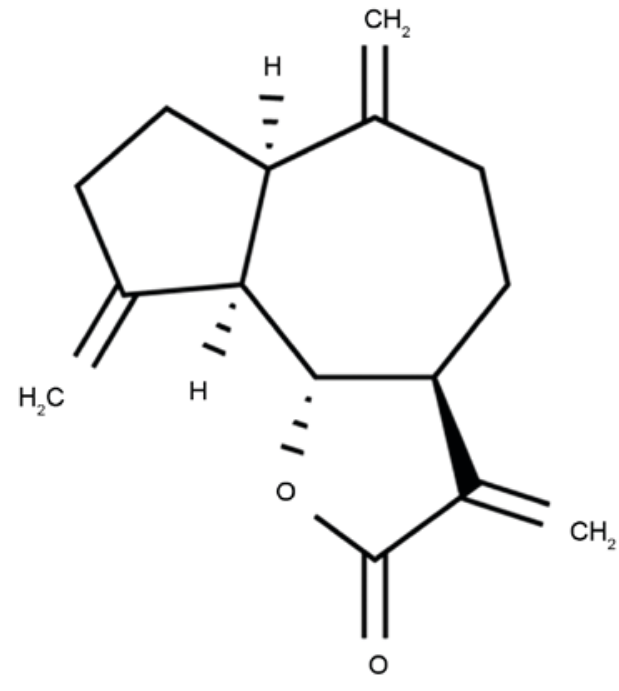

Figure 1. Chemical structure of dehydrocostus lactone.

Caspase-3 and caspase-9 activity levels. Recombinant HPV-18 HaCaT cells $\left(1 \times 10^{3}\right.$ cell/well) were seeded in 6-well plates and treated with $2 \mu \mathrm{l}$ of DMSO or dehydrocostus lactone $(2.5,5$ and $10 \mu \mathrm{g} / \mathrm{ml})$ for $48 \mathrm{~h}$ at $37^{\circ} \mathrm{C}$. Cells were subsequently washed with PBS and lysed using radioimmunoprecipitation assay (RIPA) lysis buffer (Beyotime Institute of Biotechnology, Nanjing, China). Cell extracts were clarified by centrifugation at $10,000 \mathrm{x}$ g for $15 \mathrm{~min}$ at $4^{\circ} \mathrm{C}$ and protein concentration was measured by a BCA assay. Proteins $(10 \mu \mathrm{g}$ per sample) were incubated with N-acetyl-Asp-Glu-Val-Asp p-nitroanilide (also termed Ac-DEVD-pNA; Beyotime Institute of Biotechnology) for $2 \mathrm{~h}$ at $37^{\circ} \mathrm{C}$. The activity levels of caspase- 3 and caspase- 9 were subsequently determined using the SpectraMax 190 microplate reader at $405 \mathrm{~nm}$.

Apoptosis rate. Recombinant HPV-18 HaCaT cells $\left(1 \times 10^{3}\right.$ cells/well) were seeded into 6 -well plates and treated with $2 \mu 1$ of DMSO or dehydrocostus lactone $(2.5,5$ and $10 \mu \mathrm{g} / \mathrm{ml})$ for $48 \mathrm{~h}$ at $37^{\circ} \mathrm{C}$. Cells were subsequently washed with PBS and fixed with $4 \%$ paraformaldehyde for $15 \mathrm{~min}$ at room temperature. Cells were then stained with $5 \mu \mathrm{l}$ of Annexin V-fluorescein isothiocyanate (cat. no. 556570; BD Biosciences, San Jose, CA, USA) and $5 \mu 1$ of propidium iodide (cat. no. 556570; BD Biosciences) for $20 \mathrm{~min}$ in darkness at room temperature. Cell apoptosis rate was then detected using a flow cytometer (C6; BD Biosciences) and analyzed using FlowJo software (version 7.6.1; FlowJo LLC, Ashland, OR, USA).

Reverse transcription-quantitative polymerase chain reaction $(R T-q P C R)$. Total cellular RNA was extracted from $\mathrm{HaCaT}$ cells using the TRIzol reagent (Invitrogen; Thermo Fisher Scientific, Inc.). Total RNA (500 ng) was reverse-transcribed using a First-Strand cDNA Synthesis kit (GeneCopoeia, Inc., Rockville, MD, USA) at $42^{\circ} \mathrm{C}$ for $2 \mathrm{~min}, 37^{\circ} \mathrm{C}$ for $30 \mathrm{~min}$ and $85^{\circ} \mathrm{C}$ for $5 \mathrm{sec}$. Following this, qPCR was performed using SYBR Green PCR Master Mix (cat. no. 303410; Takara Biotechnology Co., Ltd., Dalian, China) by a LightCycler ${ }^{\circledR} 2.0$ apparatus (Roche Applied Science, Mannheim, Germany). The thermocycling conditions were as follows: $94^{\circ} \mathrm{C}$ for $5 \mathrm{~min}$, followed by 40 cycles of $94^{\circ} \mathrm{C}$ for $30 \mathrm{sec}$, annealing at $60^{\circ} \mathrm{C}$ for 

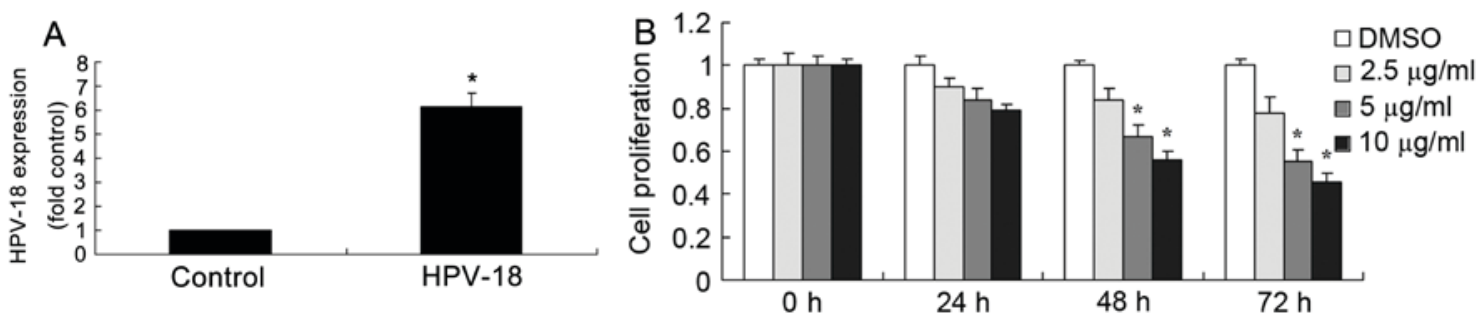

Figure 2. Dehydrocostus lactone reduced cell proliferation of HaCaT cells. (A) Determination of HPV-18 expression using quantitative-polymerase chain reaction. (B) An MTT assay was performed to determine the effect of treatment with $2.5,5$ and $10 \mu \mathrm{g} / \mathrm{ml}$ dehydrocostus lactone for $0,24,48$ and $72 \mathrm{~h}$ on the proliferation of recombinant human papilloma virus-18 HaCaT cells. DMSO was used as control treatment. "P<0.01 vs. DMSO control group. DMSO, dimethyl sulfoxide.

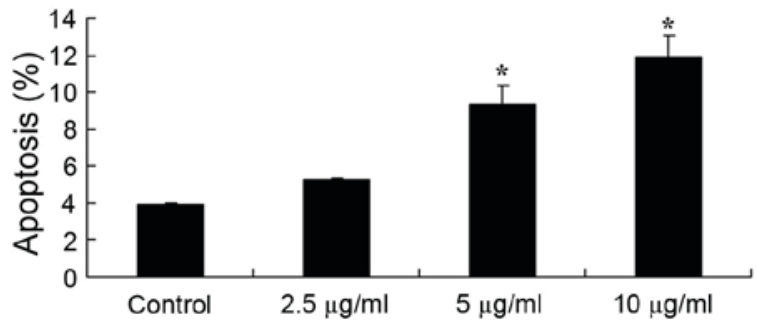

Figure 3. Dehydrocostus lactone induced apoptosis in HaCaT cells. The effects of $2.5,5$ and $10 \mu \mathrm{g} / \mathrm{ml}$ dehydrocostus lactone treatment for $48 \mathrm{~h}$ on apoptosis levels in recombinant human papilloma virus-18 $\mathrm{HaCaT}$ cells were determined. DMSO was used as control treatment. ${ }^{*} \mathrm{P}<0.01$ vs. DMSO control group. DMSO, dimethyl sulfoxide.

$30 \mathrm{sec}$, and a final extension of $72^{\circ} \mathrm{C}$ for $30 \mathrm{sec}$. Primers used for amplification were as follows: HPV-18 forward, 5'-TAC CTGTGTCACAAGCCGTT-3' and reverse, 5'-CAGCAGTGT AAGCAACGACC-3'; GAPDH forward, 5'-ACAGCAACA GGGTGGTGGAC-3' and reverse, 5'-TTTGAGGGTGCACGA ACTT-3'. The data were analyzed using the $2^{-\Delta \Delta \mathrm{Cq}}$ method (16).

Western blot analysis. Recombinant HPV-18 HaCaT cells $\left(1 \times 10^{6}\right.$ cell/well $)$ were seeded in 6 -well plates and treated with either $2 \mu \mathrm{l}$ of DMSO or $2 \mu \mathrm{l}$ of dehydrocostus lactone $(2.5,5$ and $10 \mu \mathrm{g} / \mathrm{ml})$ for $48 \mathrm{~h}$ at $37^{\circ} \mathrm{C}$. Cells were washed with PBS and lysed using RIPA assay. Cell extracts were clarified by centrifugation at $10,000 \mathrm{x}$ g for $15 \mathrm{~min}$ at $4^{\circ} \mathrm{C}$ and protein concentration was measured by a BCA assay. Proteins $(25 \mu \mathrm{g}$ per sample) were analyzed on an 8-10\% SDS-PAGE gel and transferred onto polyvinylidene fluoride membranes (Merck KGaA). Membranes were subsequently blocked with $5 \%$ skim milk powder in TBS- $0.1 \%$ Tween-20 for $1 \mathrm{~h}$ at $37^{\circ} \mathrm{C}$ and incubated with Bax (cat. no. sc-6236; 1:1,000; Santa Cruz Biotechnology, Inc., Dallas, TX, USA), p53 (cat. no. sc-6243; 1:1,000; Santa Cruz Biotechnology, Inc.), cyclin D1 (cat. no. sc-717; 1:500; Santa Cruz Biotechnology, Inc.), phosphatase and tensin homology (PTEN; cat. no. sc-6817-R; 1:1,000; Santa Cruz Biotechnology, Inc.), PI3K (cat. no. sc-7174; 1:500; Santa Cruz Biotechnology, Inc.), Akt (cat. no. sc-8312; 1:500; Santa Cruz Biotechnology, Inc.), phosphorylated (p)-Akt (cat. no. sc-16646-R; 1:500; Santa Cruz Biotechnology, Inc.) and GAPDH (cat. no. sc-25778; 1:2,000; Santa Cruz Biotechnology, Inc.) primary antibodies at $4^{\circ} \mathrm{C}$ overnight, which was followed by incubation with goat anti-rabbit immunoglobulin G-horseradish peroxidase (cat. no. sc-2004; 1:5,000; Santa Cruz Biotechnology, Inc.) for $1 \mathrm{~h}$ at $37^{\circ} \mathrm{C}$. The intensity of each band was detected using BeyoECL Plus reagent (cat. no. P0018A; Beyotime Institute of Biotechnology, Nanjing, China) and quantified using ImageJ software 6.0 (National Institutes of Health, Bethesda, MD, USA).

Statistical analysis. Data are presented as the mean + standard deviation using SPSS v.20 (IBM Corp., Armonk, NY, USA). All experiments were performed in triplicate. One-way analysis of variance followed by Tukey post hoc test was performed to determine the significance of differences among the experimental groups. $\mathrm{P}<0.05$ was considered to indicate a statistically significant difference.

\section{Results}

Dehydrocostus lactone reduces the proliferation of recombinant $\mathrm{HPV}-18 \mathrm{HaCaT}$ cells. The effect of dehydrocostus lactone on recombinant HPV-18 HaCaT cell proliferation was determined using an MTT assay. As revealed in Fig. 2A, transfection with HPV-18 expression plasmid significantly increased the expression of HPV-18 miRNA expression in HaCaT cells, compared with the negative control group. As demonstrated in Fig. 2B, treatment with dehydrocostus lactone reduced the proliferation of recombinant HPV-18 HaCaT cells in dose- and time-dependent manner, compared with DMSO-treated cells. In particular, 5 and $10 \mu \mathrm{g} / \mathrm{ml}$ dehydrocostus lactone for 48 or $72 \mathrm{~h}$ significantly reduced the proliferation of recombinant HPV-18 HaCaT cells, compared with the DMSO control group at the same time points (Fig. 2B).

Dehydrocostus lactone induces apoptosis in HaCaT cells. Furthermore, the present study also investigated the effect of dehydrocostus lactone on apoptosis in recombinant HPV-18 $\mathrm{HaCaT}$ cells. The results demonstrated that the apoptosis rate of recombinant HPV-18 HaCaT cells was significantly increased following treatment for $48 \mathrm{~h}$ with 5 and $10 \mu \mathrm{g} / \mathrm{ml}$ dehydrocostus lactone, compared with the DMSO control group (Fig. 3).

Dehydrocostus lactone promotes caspase-3/9 activity in HaCaT cells. The activities of caspase-3/9 in DMSO- and dehydrocostus lactone-treated recombinant HPV-18 HaCaT cells were also investigated in the present study. As demonstrated in Fig. 4, dehydrocostus lactone treatment for $48 \mathrm{~h}$ also led to significant increases in the caspase-3/9 activities of recombinant HPV-18 HaCaT cells at concentrations of 5 and $10 \mu \mathrm{g} / \mathrm{ml}$, compared with the DMSO control group. 
A

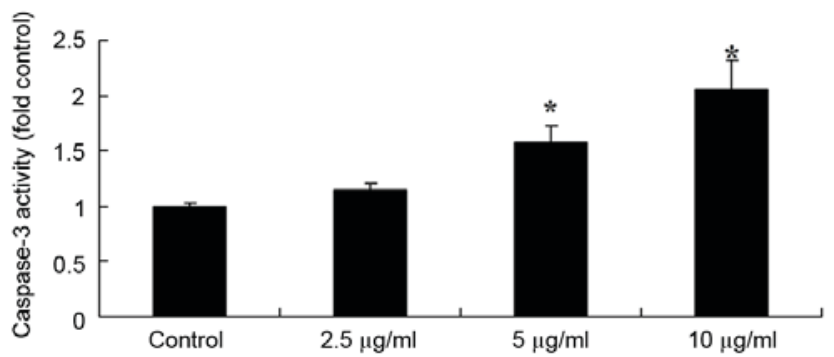

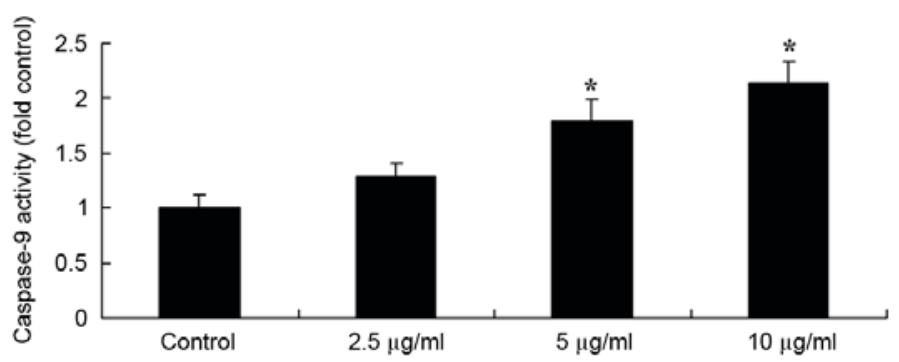

Figure 4. Dehydrocostus lactone increased the caspase-3/9 activities in HaCaT cells. Dehydrocostus lactone increased the activities of (A) caspase-3 and (B) caspase-9 in recombinant human papilloma virus-18 HaCaT cells. DMSO was used as control treatment, and $2.5,5$ and $10 \mu \mathrm{g} / \mathrm{ml}$ concentrations of dehydrocostus lactone were employed. "P<0.01 vs. DMSO control group. DMSO, dimethyl sulfoxide.

Dehydrocostus lactone promotes Bax and p53 protein expression, and suppresses the protein expression of cyclin D1 in HaCaT cells. To observe the effect of dehydrocostus lactone on Bax, p53 and cyclin D1 protein expression in recombinant HPV-18 HaCaT cells, Bax and p53 protein expression was determined by western blot analysis. Dehydrocostus lactone (5 and $10 \mu \mathrm{g} / \mathrm{ml}$ ) treatment for $48 \mathrm{~h}$ significantly increased Bax and p53 protein expression, and suppressed cyclin D1 protein expression in recombinant HPV-18 HaCaT cells, compared with the DMSO control group (Fig. 5).

Dehydrocostus lactone increases PTEN protein expression and downregulates the PI3K/Akt signaling pathway in $\mathrm{HaCaT}$ cells. To determine the effect of dehydrocostus lactone on PTEN protein expression and the PI3K/Akt signaling pathway in recombinant HPV-18 HaCaT cells, western blot analysis was performed. The results in Fig. 6 demonstrate that dehydrocostus lactone ( 5 and $10 \mu \mathrm{g} / \mathrm{ml}$ ) treatment for $48 \mathrm{~h}$ significantly increased PTEN protein expression, and suppressed PI3K and p-Akt levels in recombinant HPV-18 HaCaT cells, compared with the DMSO control group.

\section{Discussion}

A previous study on CA has indicated that human immune responses, particularly cellular immune responses, are the principal factor determining the outcome of CA (2). Patients with deficits in the cellular immune response, including patients with acquired immune deficiency syndrome, Hodgkin lymphoma, malignant lymphoma and chronic lymphocytic leukemia, are at an increased risk of being affected by HPV (6). Patients that are taking immunosuppressive drugs, particularly those following renal transplantation and heart transplants, are prone to broad and persistent warts (6). The present study demonstrated that dehydrocostus lactone significantly reduced the proliferation of recombinant HPV-18 HaCaT cells, which indicates that it may be useful for the prevention/treatment of CA.

$\mathrm{CA}$ is a type of benign proliferative disease of the skin membrane at the genitals, anus and perineum (17). It is a gynecological disease that is commonly observed in the clinic. The primary methods of its transmission between individuals are by sexual contact or through indirect contact, and mother-to-child vertical transmission (17). With the development of the economy, and increased international and domestic exchanges, CA has become a sexually transmitted disease with one of the highest growth rates (18). A previous study demonstrated that the genesis and development of CA involves a complicated gene regulation process (18). Humans are the only natural host of HPV (6); following infection of human squamous epithelial cells by HPV, cells exhibit abnormal proliferation and apoptosis. The results of the present study demonstrated that dehydrocostus lactone significantly reduced proliferation, and increased apoptosis, in recombinant HPV-18 HaCaT cells. Furthermore, Sun et al (15) reported that dehydrocostus lactone suppressed the proliferation of colorectal carcinoma cells via downregulation of eukaryotic translation initiation factor $4 \mathrm{E}$ expression.

Apoptosis is a type of programmed cell death and abnormal apoptosis levels may lead to the excessive proliferation of cells (19). Clinically, a minority of patients with CA develop large CA due to excessive hyperplasia in a short period of time (20). Additionally, CA may develop and deteriorate further in certain patients, leading to the genesis of malignant tumors (20). The caspase-3 protein family and Bax have been demonstrated to enhance apoptosis (21). However, few studies have investigated their roles in hyperplastic diseases of the skin. Caspase-3 and Bax have important roles in apoptosis $(21,22)$, therefore, the present study investigated the activity/expression of these proteins, and the results demonstrated that dehydrocostus lactone significantly increased caspase-3/9 activities and induced Bax protein expression in recombinant HPV-18 HaCaT cells.

A previous study demonstrated that the PI3K/Akt signaling pathway is closely associated with CA (23). Additionally, studies concerning $\mathrm{CA}$ have demonstrated that the PI3K/Akt signal transduction pathway is involved in resisting Fas regulation and the apoptotic process (23). Therefore, the activation of the PI3K/Akt signal transduction pathway may lead to the genesis of CA (23), and its mechanism of action may involve the abnormal expression of PTEN (24). A further study regarding CA also reported that PI3K/Akt signaling may increase the expression of growth factor receptors to promote mitosis (23). Therefore, the PI3K/Akt signaling pathway is closely associated with the genesis and development of CA (24), and indicators of PI3K/Akt signaling pathway activity in CA tissues may be used as an indicator to evaluate CA malignant grade (24).

The PI3K/Akt signaling pathway is an important signaling pathway in various biological processes. It is a signal transduction pathway that has one of the strongest associations with cell 

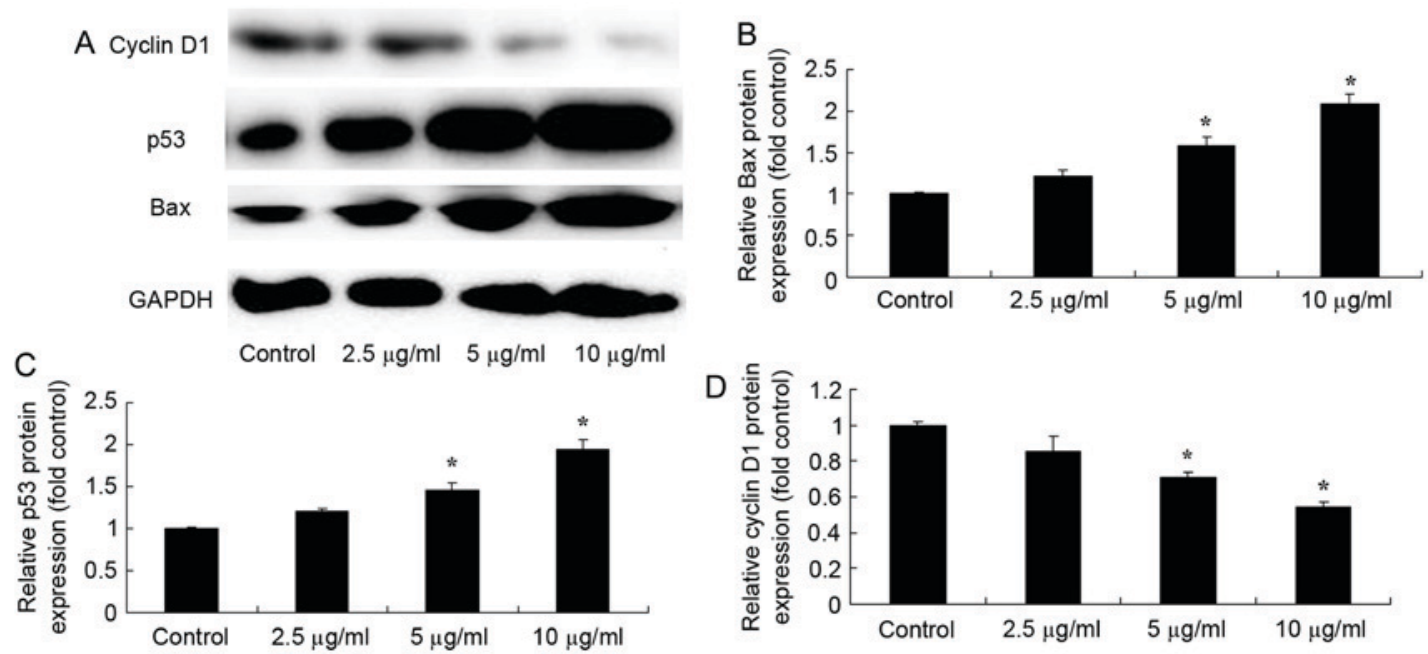

Figure 5. Dehydrocostus lactone promoted Bax and p53 protein expression, and suppressed cyclin D1 protein expression in HaCaT cells. (A) Representative western blot of Bax, p53 and cyclin D1 protein expression. Densitometric and statistical analysis of (B) Bax, (C) p53 and (D) cyclin D1 protein expression in recombinant human papilloma virus-18 HaCaT cells. DMSO was used as control treatment, and 2.5, 5 and $10 \mu \mathrm{g} / \mathrm{ml}$ concentrations of dehydrocostus lactone were employed for 48 h. ${ }^{*} \mathrm{P}<0.01$ vs. DMSO control group. Bax, Bcl-2-associated X; DMSO, dimethyl sulfoxide.
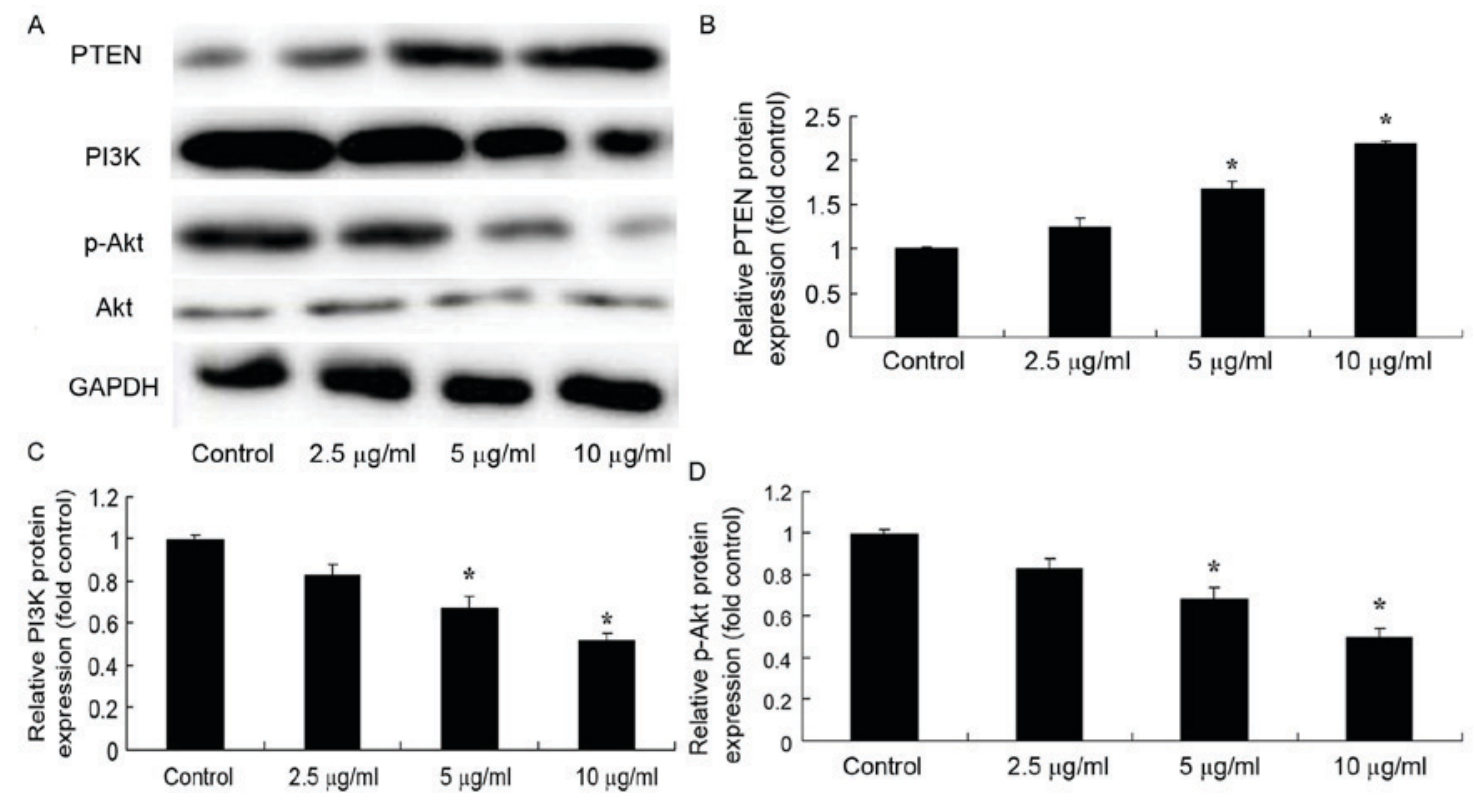

Figure 6. Dehydrocostus lactone upregulated PTEN protein expression and downregulated the PI3K/Akt signaling pathway in HaCaT cells. (A) Representative western blot of PTEN, PI3K, Akt and p-Akt protein levels. Densitometric and statistical analysis of (B) PTEN, (C) PI3K and (D) p-Akt protein levels in recombinant human papilloma virus-18 $\mathrm{HaCaT}$ cells. DMSO was used as control treatment, and 2.5, 5 and $10 \mu \mathrm{g} / \mathrm{ml}$ concentrations of dehydrocostus lactone were employed for 48 h. "P<0.01 vs. DMSO control group. PTEN, phosphatase and tensin homolog; PI3K, phosphatidylinositol 3-kinase; p-, phosphorylated-; DMSO, dimethyl sulfoxide.

proliferation and apoptosis (23). A previous study demonstrated that the PI3K/Akt signaling pathway is abnormally activated in various tumor types (23). The activation of the signal transduction pathway inhibits cell apoptosis induced by various stimuli, and promotes cell cycle progression to promote cell survival and proliferation (25). In addition, this signaling pathway has important roles in angiopoiesis and tumor formation, and is implicated in the invasion and metastasis of tumors (26). The results of the present study demonstrated that dehydrocostus lactone significantly increased PTEN protein expression, and downregulated PI3K and p-AKT protein expression, in recombinant HPV-18 HaCaT cells. Furthermore, Jiang et al (27) demonstrated that dehydrocostus lactone inhibited the proliferation and invasion of cervical cancer cells via the PI3K/Akt signaling pathway.

In conclusion, the results of the present study indicate that dehydrocostus lactone may suppress cell growth and induce apoptosis in recombinant HPV-18 HaCaT cells via the PI3K/Akt signaling pathway, and suggests that dehydrocostus lactone may exhibit anti-condyloma acuminatam effects. This novel target of dehydrocostus lactone may provide a potential prognostic marker and therapeutic target for CA patients. Future studies should investigate the effects of dehydrocostus lactone using animal models and investigate its effect on genital warts in a clinical setting. 


\section{Acknowledgements}

Not applicable.

\section{Funding}

No funding was received.

\section{Availability of data and materials}

The analysed data sets generated during the study are available from the corresponding author on reasonable request.

\section{Authors' contributions}

WL designed the study. YBM, YQM and TL performed the experiments. WL and YBM analysed the data. WL wrote the manuscript.

\section{Ethics approval and consent to participate}

Not applicable.

\section{Consent for publication}

Not applicable.

\section{Competing interests}

The authors declare that they have no competing interests.

\section{References}

1. Wang X, Ha T, Hu Y, Lu C, Liu L, Zhang X, Kao R, Kalbfleisch J, Williams D and Li C: MicroRNA-214 protects against hypoxia/reoxygenation induced cell damage and myocardial ischemia/reperfusion injury via suppression of PTEN and Bim1 expression. Oncotarget 7: 86926-86936, 2016.

2. Li D, Liu J, Guo B, Liang C, Dang L, Lu C, He X, Cheung HY, $\mathrm{Xu} \mathrm{L}, \mathrm{Lu} \mathrm{C}$, et al: Osteoclast-derived exosomal miR-214-3p inhibits osteoblastic bone formation. Nat Commun 7: 10872, 2016.

3. Chu Q, Sun Y, Cui J and Xu T: Inducible microRNA-214 contributes to the suppression of NF- $\kappa \mathrm{B}$-mediated inflammatory response via targeting myd88 gene in fish. J Biol Chem 292: 5282-5290, 2017

4. Song X, Wang CT and Geng XH: MicroRNA-29a promotes apoptosis of monocytes by targeting STAT3 during sepsis. Genet Mol Res 14: 13746-13753, 2015.

5. Hyun J, Choi SS, Diehl AM and Jung Y: Potential role of Hedgehog signaling and microRNA-29 in liver fibrosis of IKK $\beta$-deficient mouse. J Mol Histol 45: 103-112, 2014.

6. Wang ZH, Zhang JL, Duan YL, Zhang QS, Li GF and Zheng DL: MicroRNA-214 participates in the neuroprotective effect of Resveratrol via inhibiting $\alpha$-synuclein expression in MPTP-induced Parkinson's disease mouse. Biomed Pharmacother 74: 252-256, 2015.

7. Li X, Kong M, Jiang D, Qian J, Duan Q and Dong A: MicroRNA-150 aggravates $\mathrm{H} 2 \mathrm{O} 2$-induced cardiac myocyte injury by down-regulating c-myb gene. Acta Biochim Biophys Sin (Shanghai) 45: 734-741, 2013.

8. Bagge A, Clausen TR, Larsen S, Ladefoged M, Rosenstierne MW, Larsen L, Vang O, Nielsen JH and Dalgaard LT: MicroRNA-29a is up-regulated in beta-cells by glucose and decreases glucose-stimulated insulin secretion. Biochem Biophys Res Commun 426: 266-272, 2012.

9. Yang K, Cao W, Hao X, Xue X, Zhao J, Liu J, Zhao Y, Meng J, Sun B, Zhang J and Liang XJ: Metallofullerene nanoparticles promote osteogenic differentiation of bone marrow stromal cells through BMP signaling pathway. Nanoscale 5: 1205-1212, 2013.
10. Sun Y, Lu CM, Song Z, Xu KK, Wu SB and Li ZJ: Expression and regulation of microRNA-29a and microRNA-29c in early diabetic rat cataract formation. Int J Ophthalmol 9: 1719-1724, 2016.

11. Dippel DW, Majoie CB, Roos YB, van der Lugt A, van Oostenbrugge RJ, van Zwam WH, Lingsma HF, Koudstaal PJ, Treurniet KM, van den Berg LA, et al: Influence of device choice on the effect of intra-arterial treatment for acute ischemic stroke in MR CLEAN (multicenter randomized clinical trial of endovascular treatment for acute ischemic stroke in the Netherlands). Stroke 47: 2574-2581, 2016.

12. Kawakami S, Tahara Y, Noguchi T, Yagi N, Kataoka Y, Asaumi Y, Nakanishi M, Goto Y, Yokoyama H, Nonogi $\mathrm{H}$, et al: Time to reperfusion in ST-segment elevation myocardial infarction patients with vs. Without pre-hospital mobile telemedicine 12-lead electrocardiogram transmission. Circ J 80: 1624-1633, 2016.

13. Hill MD, Demchuk AM, Goyal M, Jovin TG, Foster LD, Tomsick TA, von Kummer R, Yeatts SD, Palesch YY and Broderick JP; IMS3 Investigators: Alberta stroke program early computed tomography score to select patients for endovascular treatment: Interventional management of stroke (IMS)-III trial. Stroke 45: 444-449, 2014.

14. Zhu Z, Fu Y, Tian D, Sun N, Han W, Chang G, Dong Y, Xu X, Liu Q, Huang D and Shi FD: Combination of the immune modulator fingolimod with alteplase in acute ischemic stroke: A pilot trial. Circulation 132: 1104-1112, 2015.

15. Sun X, Kang H, Yao Y, et al: Dehydrocostus lactone suppressed the proliferation, migration, and invasion of colorectal carcinoma through the downregulation of eIF4E expression. Anticancer Drugs 26: 641-648, 2015.

16. Livak KJ and Schmittgen TD: Analysis of relative gene expression data using real-time quantitative PCR and the 2(-Delta Delta C(T)) method. Methods 25: 402-408, 2001.

17. Li R, Liu J, Li Q, Chen G and Yu X: miR-29a suppresses growth and metastasis in papillary thyroid carcinoma by targeting AKT3. Tumour Biol 37: 3987-3996, 2016.

18. Zhou H, Guo W, Zhao Y, Wang Y, Zha R, Ding J, Liang L, Yang G, Chen Z, Ma B and Yin B: MicroRNA-135a acts as a putative tumor suppressor by directly targeting very low density lipoprotein receptor in human gallbladder cancer. Cancer Sci 105: 956-965, 2014.

19. Fang Y, Shen H, Li H, Cao Y, Qin R, Long L, Zhu X, Xie C and Xu W: miR-106a confers cisplatin resistance by regulating PTEN/Akt pathway in gastric cancer cells. Acta Biochim Biophys Sin (Shanghai) 45: 963-972, 2013.

20. Li H, Xu H, Shen H and Li H: microRNA-106a modulates cisplatin sensitivity by targeting PDCD4 in human ovarian cancer cells. Oncol Lett 7: 183-188, 2014.

21. Rothschild SI, Gautschi O, Batliner J, Gugger M, Fey MF and Tschan MP: MicroRNA-106a targets autophagy and enhances sensitivity of lung cancer cells to Src inhibitors. Lung Cancer 107: 73-83, 2017.

22. Chen L, Zhang F, Sheng XG, Zhang SQ, Chen YT and Liu BW: MicroRNA-106a regulates phosphatase and tensin homologue expression and promotes the proliferation and invasion of ovarian cancer cells. Oncol Rep 36: 2135-2141, 2016.

23. Ku SK and Bae JS: Antithrombotic activities of wogonin and wogonoside via inhibiting platelet aggregation. Fitoterapia 98: 27-35, 2014.

24. Ge X, Leung TM, Arriazu E, Lu Y, Urtasun R, Christensen B, Fiel MI, Mochida S, Sørensen ES and Nieto N: Osteopontin binding to lipopolysaccharide lowers tumor necrosis factor- $\alpha$ and prevents early alcohol-induced liver injury in mice. Hepatology 59: 1600-1616, 2014.

25. Yang SD, Ma L, Yang DL and Ding WY: Combined effect of $17 \beta$-estradiol and resveratrol against apoptosis induced by interleukin-1 $\beta$ in rat nucleus pulposus cells via PI3K/Akt/caspase-3 pathway. PeerJ 4: e1640, 2016.

26. Chen C, Guo D and Lu G: Wogonin protects human retinal pigment epithelium cells from LPS-induced barrier dysfunction and inflammatory responses by regulating the TLR4/NF- $\mathrm{B}$ signaling pathway. Mol Med Rep 15: 2289-2295, 2017.

27. Jiang E, Sun X, Kang H, et al: Dehydrocostus Lactone Inhibits Proliferation, Antiapoptosis, and Invasion of Cervical Cancer Cells Through PI3K/Akt Signaling Pathway. Int J Gynecol Cancer 25: 1179-1186, 2015. 